Article

\title{
Conserved Cu-MicroRNAs in Arabidopsis thaliana Function in Copper Economy under Deficiency
}

\author{
Muhammad Shahbaz and Marinus Pilon *(i) \\ Biology Department, Colorado State University, Fort Collins, CO 80523-1878, USA; ms@sppg.ca \\ * Correspondence: pilon@colostate.edu; Tel.: 1-970-495-4390
}

Received: 1 May 2019; Accepted: 24 May 2019; Published: 29 May 2019

check for updates

\begin{abstract}
Copper $(\mathrm{Cu})$ is a micronutrient for plants. Three small RNAs, which are up-regulated by $\mathrm{Cu}$ deficiency and target transcripts for $\mathrm{Cu}$ proteins, are among the most conserved microRNAs in plants. It was hypothesized that these $\mathrm{Cu}$-microRNAs help save $\mathrm{Cu}$ for the most essential $\mathrm{Cu}$-proteins under deficiency. Testing this hypothesis has been a challenge due to the redundancy of the $\mathrm{Cu}$ microRNAs and the properties of the regulatory circuits that control $\mathrm{Cu}$ homeostasis. In order to investigate the role of $\mathrm{Cu}$-microRNAs in $\mathrm{Cu}$ homeostasis during vegetative growth, we used a tandem target mimicry strategy to simultaneously inhibit the function of three conserved Cu-microRNAs in Arabidopsis thaliana. When compared to wild-type, transgenic lines that express the tandem target mimicry construct showed reduced Cu-microRNA accumulation and increased accumulation of transcripts that encode $\mathrm{Cu}$ proteins. As a result, these mimicry lines showed impaired photosynthesis and growth compared to wild type on low $\mathrm{Cu}$, which could be ascribed to a defect in accumulation of plastocyanin, a Cu-containing photosynthetic electron carrier, which is itself not a Cu-microRNA target. These data provide experimental support for a $\mathrm{Cu}$ economy model where the $\mathrm{Cu}$-microRNAs together function to allow maturation of essential $\mathrm{Cu}$ proteins under impending deficiency.
\end{abstract}

Keywords: plastocyanin; photosynthesis; copper deficiency; Cu-microRNA; copper protein; target mimicry

\section{Introduction}

Copper deficiency in plants leads to defects in photosynthesis, chlorosis, reduced respiration, and wilting of leaves. Copper is not a "mobile" element. This means that under impending deficiency, $\mathrm{Cu}$ is not efficiently transported from older tissues to newly developing leaves, which become chlorotic [1]. In green tissue, the majority of $\mathrm{Cu}$ is found in the chloroplast [2,3]. Plastocyanin (PC) is a blue $\mathrm{Cu}$ protein that mediates electron transfer from the cytochrome- $b_{6} f$ complex to photosystem I (PSI) in the thylakoid lumen of oxygenic photosynthetic organisms [4]. Arabidopsis has two genes for PC, PC1 (PETE1) and PC2 (PETE2). The PC2 protein is more abundant and responsive to Cu $[5,6]$. PC2 accumulation is a consequence of protein stability due to cofactor presence and is not due to transcript abundance changes [6-8]. In higher plants, PC is the only protein that can accept electrons from the cytochrome- $b_{6} f$ complex and Arabidopsis mutants with insertions in both PC genes are seedling-lethal on soil $[9,10]$. $\mathrm{Cu}$ is also a cofactor of $\mathrm{Cu} / \mathrm{Zn}$ superoxide dismutase (CSD) proteins that function in the metabolism of reactive oxygen radicals. In Arabidopsis, CSD2 is active in the plastids, and CSD1 is active in the cytosol [11]. Both CSD1 and CSD2 receive the $\mathrm{Cu}$ cofactor from a copper chaperone called copper chaperone for superoxide dismutase, CCS [12,13]. In mitochondria, copper is required for the function of cytochrome-c oxidase (COX), the proton-pumping terminal oxidase in the respiratory electron transport chain in the inner membrane [14]. Three $\mathrm{Cu}$ atoms are bound by the core COX subunits I, II, and III, which are encoded in the mitochondrial genome. The ethylene receptors in the endomembrane system are copper-binding proteins [15,16]. All remaining Cu proteins are most 
likely apoplastic. These include the plant-specific blue copper proteins called phytocyanins, which includes plantacyanin, apoplastic ascorbate oxidases, amine oxidases, and laccases [17-24]. The laccase family has 17 members in Arabidopsis [22], and for several of these, a role in lignification and secondary growth of the vasculature has now been established $[25,26]$.

MicroRNAs that are regulated by $\mathrm{Cu}$ availability and that target mRNAs encoding for $\mathrm{Cu}$ proteins are called Cu-microRNAs [27]. The four Cu-microRNAs of Arabidopsis-miR397, miR398, miR408, and miR857-were first discovered in deep sequencing projects [28] and regulation of CSD1 and CSD2 by miR398 was shown by Sunkar et al. [29]. It was later found that miR398, and thus CSD1, CSD2, and CCS, are regulated primarily by Cu levels $[13,30]$. In addition, miR397, miR408, and miR857 regulate the abundance of other $\mathrm{Cu}$ proteins in Arabidopsis, specifically laccases and the secreted protein plantacyanin in response to $\mathrm{Cu}$ availability [31]. The $\mathrm{Cu}$-microRNAs are in turn regulated via a Cu-responsive transcription factor called SPL7 (squamosa promotor binding protein-like7), which also regulates $\mathrm{Cu}$ assimilation [8,32-34]. Three of the four Arabidopsis Cu microRNAs (miR397, miR398, and miR408) are among the most highly conserved microRNAs in plants [35]. This conservation suggests an important function. Because of the strong link with $\mathrm{Cu}$, it was hypothesized that the $\mathrm{Cu}$-microRNAs function in the $\mathrm{Cu}$ economy. According to this idea, in plants, which have symplasmic connections that allow both the sharing of nutrients and communication via small RNAs, the regulation via microRNAs provides a mechanism to save $\mathrm{Cu}$ and to allow essential $\mathrm{Cu}$ protein maturation, such as PC and COX, in actively growing cells of a tissue during impending deficiency [27]. The hypothesis rests on three legs. Two well-supported tenets are the very tight bonding of $\mathrm{Cu}$ atoms to its ligands [36] and the presence of symplasmic connections between cells in plants. The third leg of the hypothesis is that effective signaling in and between cells via microRNAs works to signal $\mathrm{Cu}$ status and that it can indeed help to tune $\mathrm{Cu}$ protein expression. This third leg needs further experimental support. The possible role of $\mathrm{Cu}$-microRNAs in the $\mathrm{Cu}$ economy is based mostly on correlative evidence with some more direct support in Arabidopsis and in poplar [30,31,33,34,37,38]. In fact, the idea that $\mathrm{Cu}$ delivery to $\mathrm{PC}$ is a priority is not supported by the observation that PC2 protein levels are strongly affected by $\mathrm{Cu}$ deficiency even if mRNA levels were not affected [6]. Do Cu microRNAs actually make a difference for $\mathrm{Cu}$ economy? To test this, we aimed to inactivate the conserved $\mathrm{Cu}$-microRNAs (miR397, miR398, and miR408) and to analyze, especially under impending deficiency, the effects on growth and $\mathrm{Cu}$ allocation to abundant and essential $\mathrm{Cu}$ proteins, such as PC1 and PC2, which are not down-regulated via a microRNA. Because $\mathrm{Cu}$ deficiency affects flower and pollen development with several compounding effects, we limited our study to the vegetative shoot before flowering [31,39].

The Cu-microRNAs are under control of SPL7 [8,32]. Because in a spl7-loss-of-function mutant, $\mathrm{Cu}$ uptake is also defective, a good test of $\mathrm{Cu}$-microRNA function requires that its regulation is uncoupled from SPL7. We have tested single microRNA loss-of-function mutants for miR398a/c and for miR408 and found no discernable phenotypes and certainly no defect in PC maturation $[3,13]$. Similarly, miR398 overexpression caused no severe phenotypes on soil or on agar media $[13,40]$. However, Zhang et al. have reported a small effect on PC accumulation due to altered miR408 expression in a hy5/spl7 background [34]. Due to properties of the SPL7-mediated system, changes in single $\mathrm{Cu}$-microRNAs can be predicted to show attenuated effects on $\mathrm{Cu}$ homeostasis because the addition or elimination of $\mathrm{Cu}$-binding targets will affect the $\mathrm{Cu}$ pool sensed by SPL7, which will reset the expression of $\mathrm{Cu}$-microRNAs and $\mathrm{Cu}$ uptake systems [27]. Due to the "dampening" properties of the system, we predict that disruption of just one $\mathrm{Cu}$-microRNA will have very small effects. Thus, perhaps all or the majority of the Cu-microRNAs must be perturbed simultaneously before strong effects on $\mathrm{Cu}$ homeostasis can be expected. We focused here on the conserved $\mathrm{Cu}$-microRNAs. Each of $m i R 397$ and miR398 have multiple loci and thus combinations (crosses) of knock-out (KO) lines to inactivate all $\mathrm{Cu}$-microRNAs are virtually impossible. We therefore used a target mimicry construct to simultaneously inhibit all the conserved Cu-microRNAs [41]. Target mimicry relies on the production of a "designed" RNA transcript, which is modified from INDUCED BY PHOSPHATE STARVATION1 (IPS1), a non-coding RNA in Arabidopsis that functions to sequester miR399, a microRNA that functions 
in the regulation of phosphate homeostasis [41]. The native IPS1 transcript contains a microRNA target site for miR399 that cannot be cleaved and that should sequester and inactivate the microRNA. The original mimicry target site in miR399 can be modified to inhibit other microRNAs [41].

\section{Results}

In order to simultaneously inhibit all three Cu-microRNAs, we designed a tandem target mimicry strategy (see Supplementary Figure S1). In this approach we modified the native IPS1 sequence [41] by replacing the miR399 target sequence with three, in tandem, target sites for miR397, miR398, and miR408, respectively. The construct was placed under the control of a constitutive 35S-CaMV promoter. The three conserved $\mathrm{Cu}$-microRNAs should be sequestered by the modified IPS1-Cu-microRNA tandem mimicry construct, which is not a target for microRNA-directed cleavage due to inserted mismatches at the predicted target cleavage sites.

Three transgenic Arabidopsis lines with high expression of the tandem mimicry construct were selected and compared to wild-type plants. To control $\mathrm{Cu}$ status, we germinated plants on $\mathrm{Cu}$ replete agar media for 10 days before transplanting the seedlings to hydroponics. We first verified that the expression in the shoot of the tandem mimicry construct was not affected by $\mathrm{Cu}$-feeding status after 3.5 weeks in hydroponics ( 5 weeks after the start of germination) (Figure 1). We used three $\mathrm{Cu}$ regimes; no $\mathrm{Cu}$ addition for mild deficiency after 3-4 weeks in this growth condition; $5 \mathrm{nM} \mathrm{CuSO}_{4}$ for $\mathrm{Cu}$-sufficient; and $50 \mathrm{nM} \mathrm{CuSO}_{4}$ for $\mathrm{Cu}$-replete, a condition where all $\mathrm{Cu}$ proteins are expected to acquire this cofactor [31]. As expected, the target mimicry construct expression was not affected by $\mathrm{Cu}$ availability (Figure 1).

The tandem target mimicry construct was designed to affect the function of the three conserved $\mathrm{Cu}$-microRNAs and prevent strong down-regulation of the transcripts for $\mathrm{Cu}$ proteins normally targeting the $\mathrm{Cu}$-microRNAs, especially in low $\mathrm{Cu}$ conditions. We investigated, using quantitative reverse transcription polymerase chain reaction (qRT-PCR), the effect of the tandem target mimicry construct on the accumulation of the three conserved $\mathrm{Cu}$-microRNAs at the three $\mathrm{Cu}$ concentrations (Figure 1). For both miR397 and miR398, three loci are present, whereas for miR408, a single locus exists. For miR397 and miR398, we utilized primers optimized to amplify the more abundant and $\mathrm{Cu}$ induced isoforms [8]. As expected, all three conserved $\mathrm{Cu}$-microRNAs were strongly regulated by $\mathrm{Cu}$ availability in the wild-type, with highest expression seen when $\mathrm{Cu}$ was omitted from the growth medium (Figure 1). Conversely, in plants grown on $50 \mathrm{nM} \mathrm{CuSO}_{4}$, the expression of all three $\mathrm{Cu}$-microRNAs was strongly repressed. Expression of the tandem target mimicry construct caused a notable reduction of all three $\mathrm{Cu}$ microRNAs. The effect on $\mathrm{Cu}$-microRNA expression was more pronounced for miR398 and miR408 compared to miR397 (Figure 1). The effect of target tandem mimicry was most pronounced at $0 \mathrm{nM}$ and $5 \mathrm{nM} \mathrm{CuSO}_{4}$, where in the wild-type, the $\mathrm{Cu}$-microRNAs accumulated. Higher expression of the mimicry construct in lines M5 and M17 correlated with a stronger effect on Cu-microRNA accumulation. 

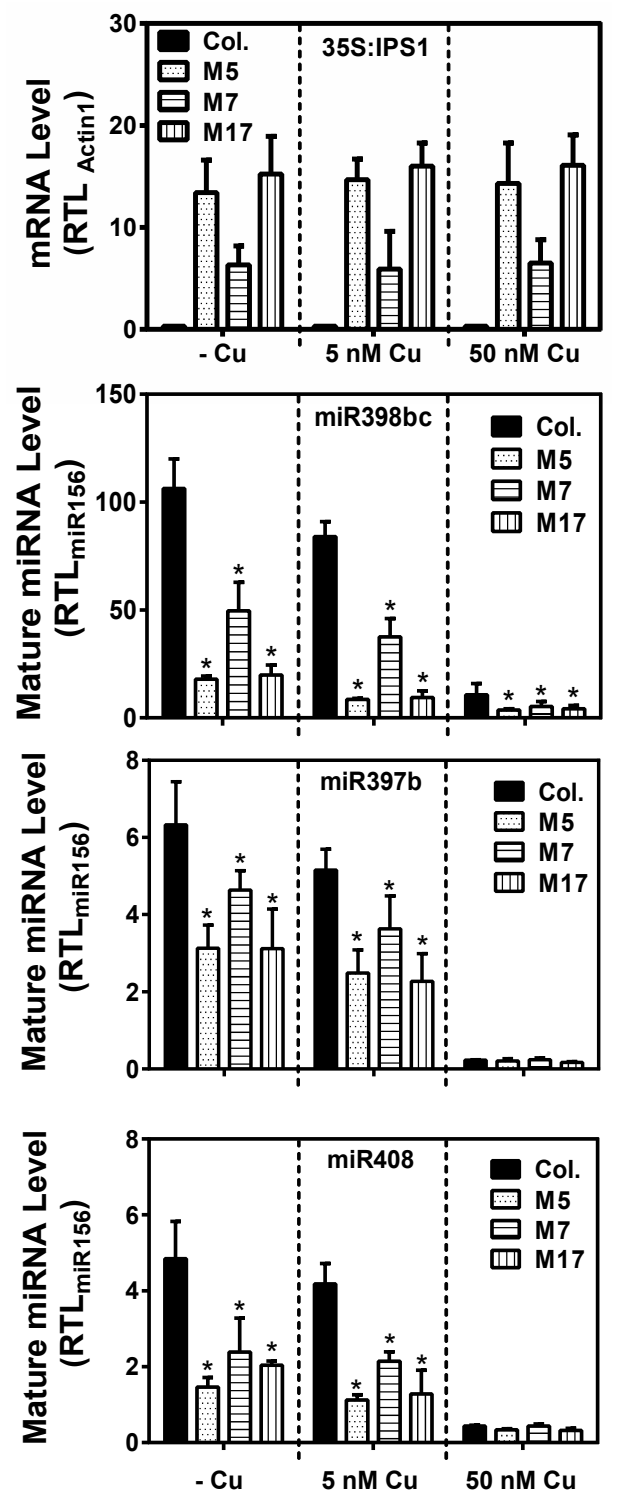

Figure 1. Expression of the IPS1 tandem target mimicry construct and three conserved Cu-microRNAs in wild type (Col) and three transgenic lines (M5, M7, and M17). 35S:IPS1 transgene relative transcript levels (RTL) were determined using qRT-PCR. Values are normalized relative to actin 1 expression. Mature microRNA levels were measured by qRT-PCR using primers designed for miR398bc, miR397b, and miR408. Relative microRNA levels were normalized to miR156 expression. All data and are given as averages $\pm \mathrm{SD}(n=3) .{ }^{*}$ indicate significant differences from the control $(p<0.05$, Student's $t$-test).

We next analyzed the effect of tandem target mimicry on the transcript levels of selected confirmed Cu-microRNA targets (Figure 2). As expected, a strong effect of tandem target mimicry was seen for all target transcripts, this effect was most pronounced under $\mathrm{Cu}$ deficiency $(-\mathrm{Cu})$. The deregulation by tandem target mimicry on Cu deficiency was strong for all the tested targets of the three conserved microRNAs (Figure 2). We conclude that accumulation of all the three conserved Cu-microRNAs was disrupted in the shoot by tandem target mimicry, and in turn this caused aberrant accumulation of transcripts encoding $\mathrm{Cu}$ proteins under $\mathrm{Cu}$ deficiency. 

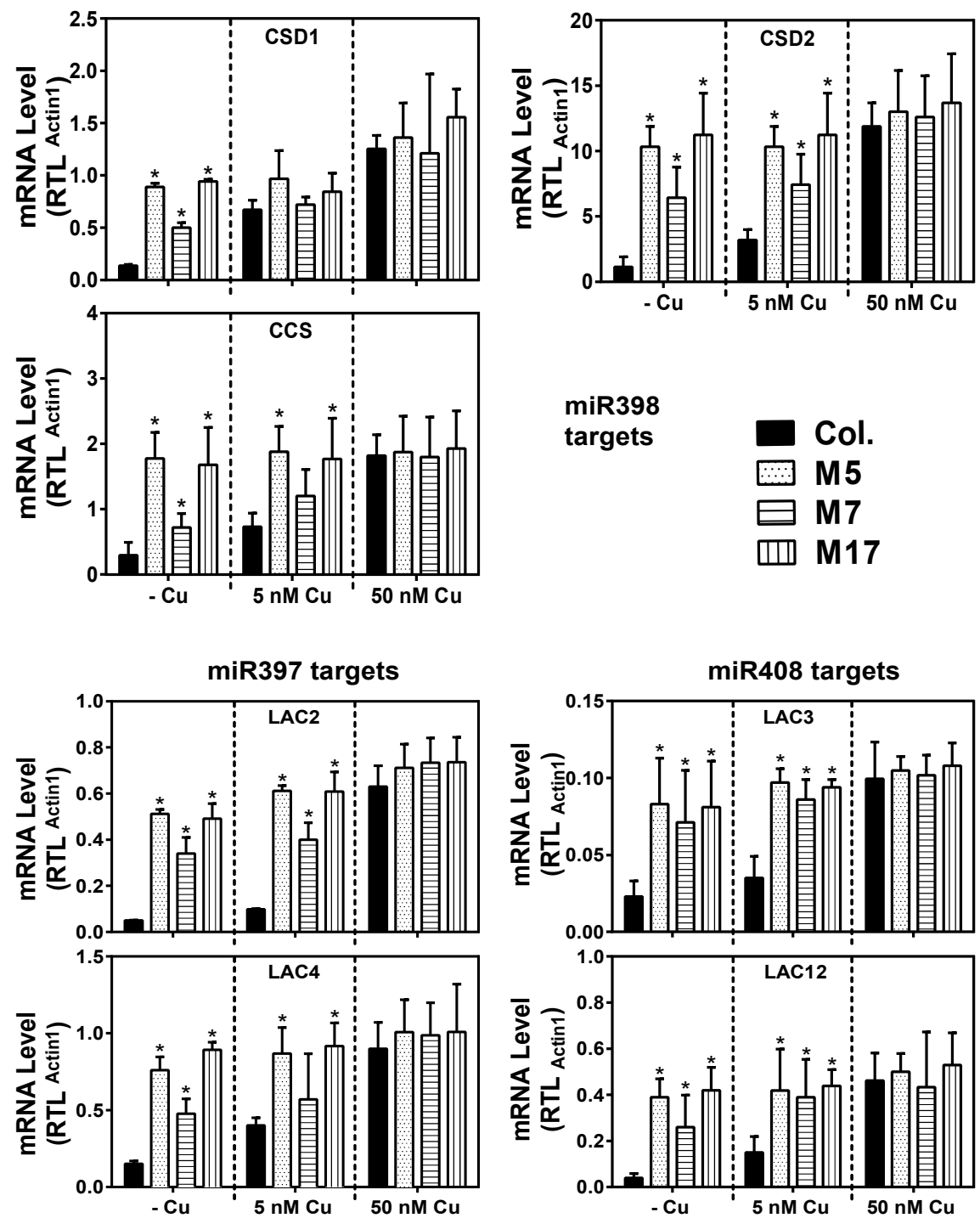

Figure 2. Expression analysis of selected Cu-microRNA target transcripts using qRT-PCR. mRNA-relative transcript levels (RTL) were normalized relative to actin 1 expression and given as averages $\pm \operatorname{SD}(n=3) .{ }^{*}$ indicate significant differences from the control $(p<0.05$, Student's $t$-test $)$.

We next analyzed vegetative growth. Because the Cu-microRNAs are highly expressed in plants grown on low $\mathrm{Cu}$ and repressed in Cu-replete conditions, phenotypes due to target mimicry were mainly expected on low $\mathrm{Cu}$ conditions. Because we were especially interested in the effects on photosynthesis during vegetative growth, we compared plants at 5 weeks of age, which in our short-day growth condition is about a week before bolting, with the onset of symptoms of deficiency showing in the wild-type, without irreversible secondary effects. Because there is $\mathrm{Cu}$ in the seeds and in the germination medium, $\mathrm{Cu}$ depletion treatment in hydroponics takes several weeks to show visible deficiency symptoms. The plants of all genotypes showed overall comparable morphology on all three conditions after 3.5 weeks in hydroponics (Figure 3A). However, when the plant biomass was measured, a clear effect was seen for $\mathrm{Cu}$ omission compared to $5 \mathrm{nM}$ and $50 \mathrm{nM} \mathrm{CuSO}_{4}$ (Figure 3B). Interestingly, in the deficient condition, a significant further reduction in biomass was seen for the three tandem target mimicry lines. We measured the elemental composition of the shoots. As expected, $\mathrm{CuSO}_{4}$ in the medium strongly affected $\mathrm{Cu}$ concentrations in the shoots. There was, however, no difference between the transgenics and wild-type, indicating that tandem target mimicry did not affect $\mathrm{Cu}$ levels (Figure 3C). Other elements did not show line-specific differences (See Table S1). In summary, tandem target mimicry for Cu-microRNAs resulted in a mild but significant effect on biomass accumulation, but only under $\mathrm{Cu}$ deficiency. 

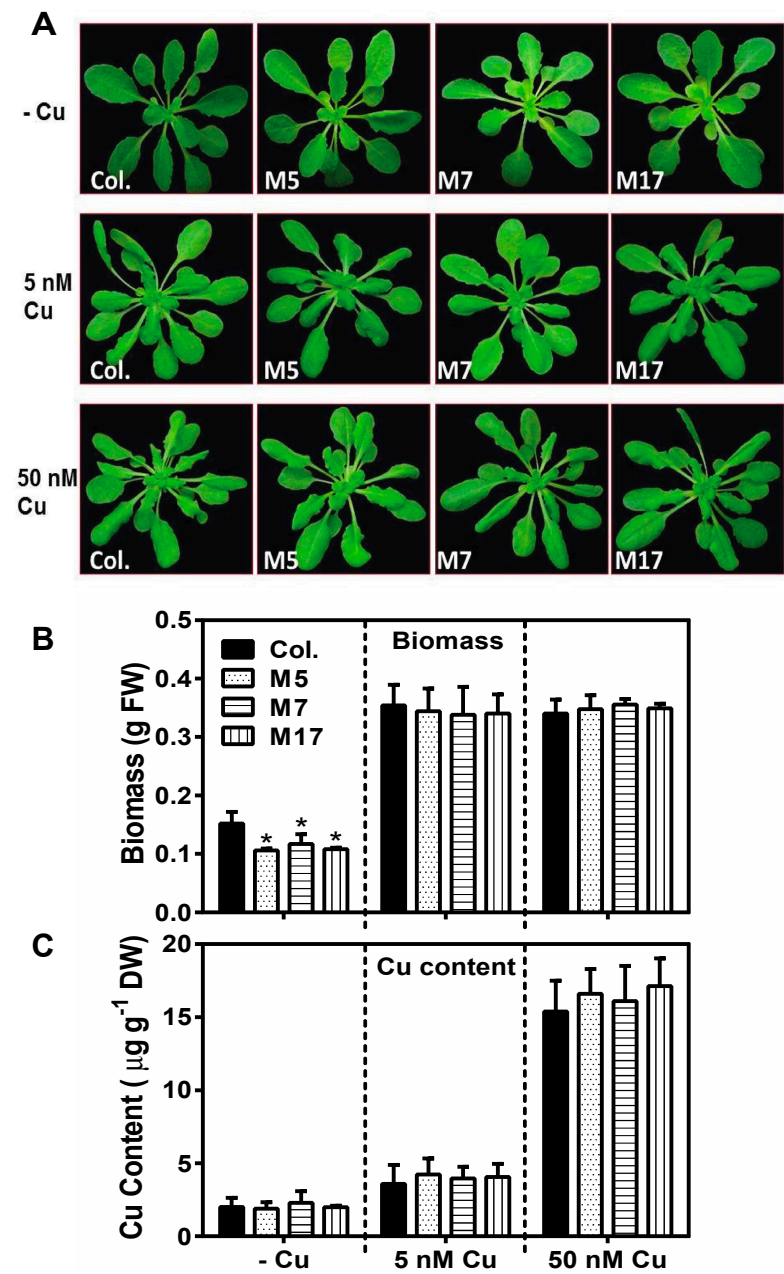

Figure 3. Effect of Cu-microRNA target mimicry on plant growth in hydroponics. (A) Representative images of 5-week-old WT (Col.); M5, M7, and M17 are All3-Cu miRNA mimicry lines. Plants were grown on 1/10th strength Hoagland solution containing 0, 5, or $50 \mathrm{nM} \mathrm{CuSO}_{4}$. (B) Fresh weight and (C) $\mathrm{Cu}$ content $\left(\mu \mathrm{g} \mathrm{g}^{-1} \mathrm{DW}\right)$ of 5-week grown plants. Values are given as averages $\pm \mathrm{SD}(n=6)$. * indicate significant differences ( $p<0.05$, Student's $t$-test).

We hypothesized that tandem target mimicry, because of the misregulated and higher expression of $\mathrm{Cu}$-microRNA targets, affected growth by limiting the pool of $\mathrm{Cu}$ available for plastocyanin, which is not a microRNA target. A lack of plastocyanin function should result in a decreased photosynthetic electron transport and a more reduced plastoquinone pool. Measurement of chlorophyll fluorescence parameters (Figure 4) indicated that $\mathrm{Cu}$ depletion in the wild-type caused a mild decrease in the flux through PSII (ФPSII), which is an estimate of photosynthetic electron transport activity. However, there was a significantly larger decrease in $\Phi P S I I$ for the three tandem target mimicry lines compared to the wild-type, but only under $\mathrm{Cu}$ deficiency. Similarly, the parameter 1-qP, which indicates the redox state of the plastoquinone pool, was affected by $\mathrm{Cu}$ depletion with a strong effect seen in tandem target mimicry. These results are strongly indicative of a defect in plastocyanin function in plants grown on low $\mathrm{Cu}$, which is exacerbated by tandem target mimicry. 


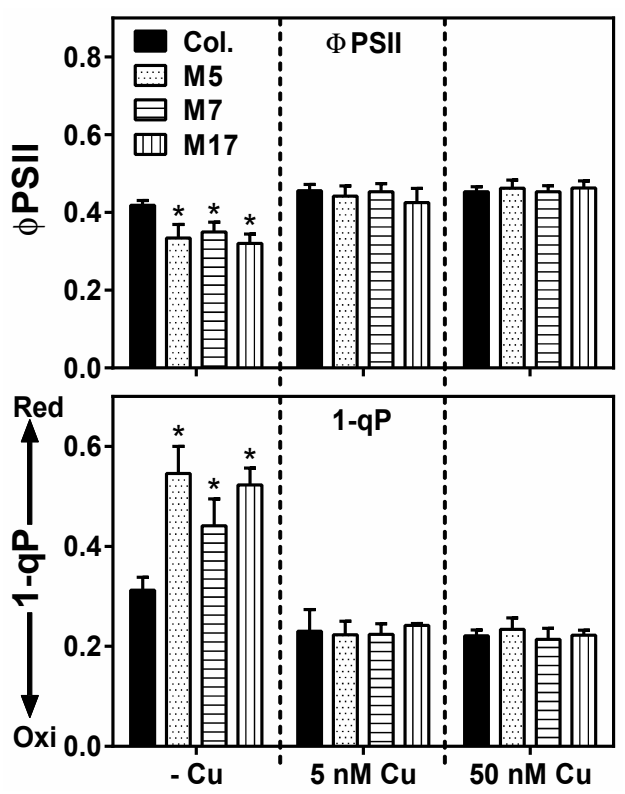

Figure 4. Photosynthetic electron transport parameters as measured by chlorophyll fluorescence. FluorCam measurement done on dark-adopted rosette leaves from WT (Col.) and transgenic lines (M5, M7, M17) growing in hydroponic culture at 0,5 , or $50 \mathrm{nM} \mathrm{CuSO}_{4}$, where values are given as averages \pm SD $(n=6)$. Top panel: $\Phi$ PSII (estimate of electron transport). Bottom panel: 1-qP (indicative of the redox state of the plastoquinone pool). ${ }^{*}$ indicate significant differences between lines within a growth condition $(p<0.05$, Student's $t$-test).

We next analyzed $\mathrm{Cu}$ protein accumulation using immunoblotting levels (Figure 5A). In Arabidopsis, two plastocyanin isoforms are expressed, $\mathrm{PC} 1$ and PC2 [10]. The more abundant PC2 isoform is known to be strongly affected at the protein level by $\mathrm{Cu}$ depletion, most likely due to a post-translational process as neither PC transcript is a target of a microRNA [6]. Indeed, Cu depletion in the wild-type resulted in a marked decrease in PC2 accumulation, while PC1 was relatively less affected (Figure 5A). Remarkably, there was a much stronger reduction in both PC isoforms in the three tandem target mimicry lines on low $\mathrm{Cu}$. The severity of the effect on PC correlated strongly with the tandem target mimicry expression level (Figures 1 and $5 \mathrm{~A}$ ). At 5 and $50 \mathrm{nM} \mathrm{CuSO}_{4}$, there was however no noticeable difference between the wild-type and transgenics. Cytochrome-c oxidase (COX) is a major Cu protein in the mitochondria where it functions as the terminal oxidase. We used antibodies specific to the Cu-binding COX core subunit II (COXII) as a proxy for COX accumulation (Figure 5A). COXII was affected by $\mathrm{Cu}$ depletion in the wild-type, albeit that the effect seemed not as strong as for PC in the chloroplast. There was a mild but noticeable larger effect of $\mathrm{Cu}$ depletion on COXII accumulation in the three target mimicry lines (Figure 5A).

We also verified accumulation of the miR398 targets: CSD1, CSD2, and CCS. As expected, accumulation of these proteins was strongly affected by $\mathrm{Cu}$ levels (Figure 5A). However, tandem target mimicry attenuated the effects of lowering $\mathrm{Cu}$ on the accumulation of these proteins. For CSD1 and CSD2 protein accumulation, the strongest effect of target mimicry was seen at $5 \mathrm{nM} \mathrm{CuSO}_{4}$, whereas for CCS protein accumulation, a strong effect was also seen at $0 \mathrm{nM} \mathrm{CuSO}_{4}$ (Figure $5 \mathrm{~A}$ ). The superoxide dismutase isozyme activity was analyzed using native gel assays (Figure 5B). As expected, the decrease in CSD1 and CSD2 protein levels resulted in a reduced CSD activity. FeSOD expression and activity, which is known to be highly $\mathrm{Cu}$ responsive and regulated via SPL7 [7,8,32], was not affected by tandem-target mimicry. In conclusion, lines that express the tandem target mimicry construct show a stronger reduction in plastocyanin and COXII levels on low $\mathrm{Cu}$, which is accompanied by an elevated accumulation and activity of the miR398 targets. 


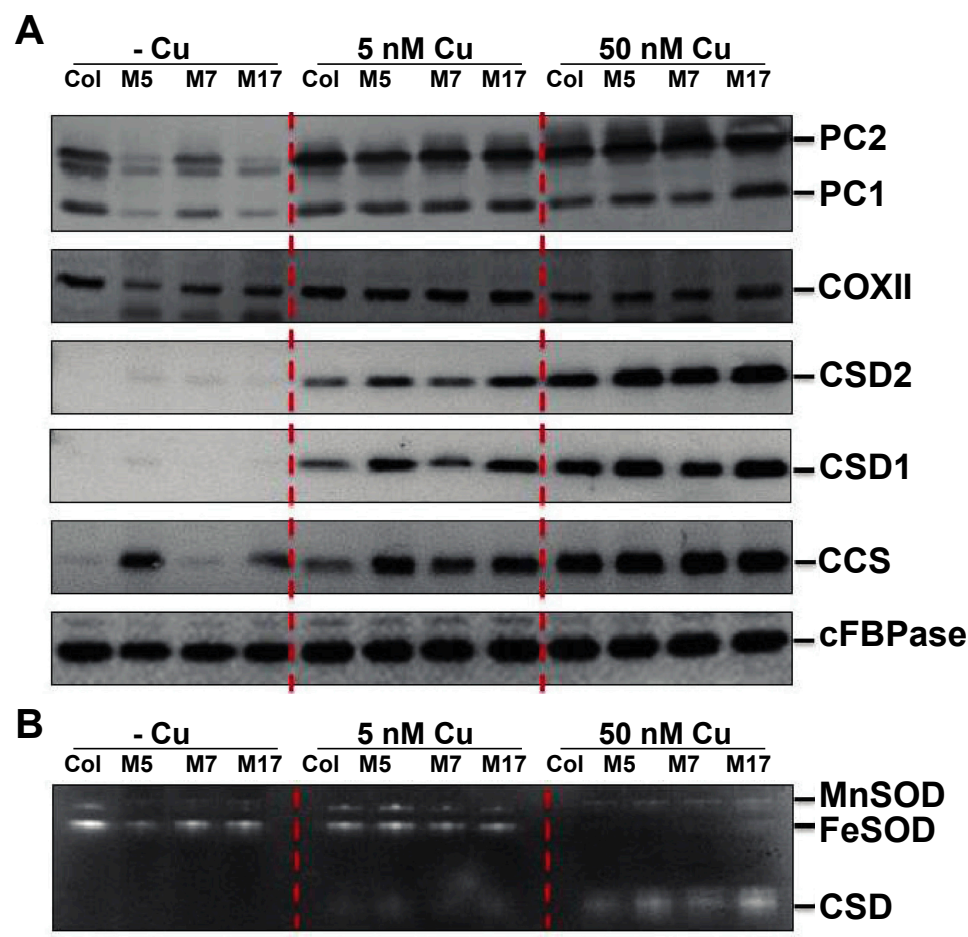

Figure 5. Comparison of $\mathrm{Cu}$ protein accumulation in wild-type $(\mathrm{Col})$ and three transgenics (M5, M7, M17). (A) Western-blot analysis using the following antibodies: PC, plastocyanin two isoforms (PC2 and PC1 are detected); COXII, cytochrome-c oxidase subunit II; CSD2 and CSD1 (chloroplast and cytosolic isoforms of $\mathrm{Cu} / \mathrm{Z}$ superoxide dismutase; and CCS, copper chaperone for $\mathrm{Cu} / \mathrm{ZnSOD}$. cFBPase was used as a loading control. Total soluble proteins $(30 \mu \mathrm{g})$ were fractioned using SDS-PAGE (15\% gel) and blotted onto nitrocellulose membranes. (B) For SOD isoform activity, total soluble proteins (30 $\mu \mathrm{g})$ were fractioned on a non-denaturing $15 \%$ acryl amide gel and stained for SOD activity. The indicated detected isoforms were identified based on known relative mobility.

\section{Discussion}

The conservation of the $\mathrm{Cu}$ microRNA sequences, their target transcripts encoding $\mathrm{Cu}$ proteins, and their regulation by $\mathrm{Cu}$ via SPL7 suggests an important function related to copper directly. Neither plastocyanin nor cytochrome-c oxidase core subunits are targets of a microRNA in plants, presumably because these proteins are indispensible. Could a role of the $\mathrm{Cu}$-microRNAs be to maintain a pool of $\mathrm{Cu}$ accessible for plastocyanin and cytochrome-c oxidase? While such a role in the Cu economy has been proposed before, the direct evidence has been limited. We aimed to test a role of conserved $\mathrm{Cu}$-microRNAs in the $\mathrm{Cu}$ economy in Arabidopsis under conditions that require photoautotrophic growth. In order to characterize a function of the conserved $\mathrm{Cu}$ microRNAs, we employed a tandem target mimicry strategy. Expression of target mimicry constructs caused a decrease in the microRNAs that were targeted (Figure 1). Such a decrease has been reported before for other microRNAs and indicates that target mimicry not only leads to target sequestration, but also causes increased microRNA instability. The Cu-microRNA deregulation was well correlated with the extent of mimicry construct expression. The tandem target mimicry approach clearly caused a deregulation of a large set of transcripts but (as expected) only on low $\mathrm{Cu}$, a condition where $\mathrm{Cu}$-microRNAs are highly expressed in the wild-type (Figures 1 and 2). As a consequence of tandem target mimicry, the plants accumulated lower amounts of the photosynthetic electron carrier plastocyanin, one of the most abundant $\mathrm{Cu}$ proteins in plants. The exacerbated reduction in plastocyanin content in tandem target mimicry lines was strongly correlated with a defect in photosynthetic electron transfer and reduced biomass on low $\mathrm{Cu}$ (Figures 3-5). These data provide strong and direct support for a role of the $\mathrm{Cu}$-microRNAs in the $\mathrm{Cu}$ economy in Arabidopsis, requiring optimization of vegetative growth under low-Cu conditions. 
While the effect on growth was relatively small and required low $\mathrm{Cu}$ to be noted, we think it is likely a strong enough phenotype to explain the conservation of the Cu-microRNAs. In this context it should be noted that the non-conserved and fourth Cu-microRNA (miR857) was not targeted here [31]. Perhaps stronger phenotypes could be observed if this fourth target was also de-regulated.

Because of the presence of $\mathrm{Cu}$ in seeds and in the germination medium, which is needed to ensure comparable development, there is a significant lag time of about two and a half to three weeks before symptoms of $\mathrm{Cu}$ deficiency manifest themselves [31]. We wanted to avoid secondary effects, and therefore grew all plants for less than four weeks in hydroponics without $\mathrm{Cu}$. We did this to avoid the compounding effects of bolting and flowering, which are strongly affected by $\mathrm{Cu}$ deficiency treatment, but only after strong and irreversible symptoms of $\mathrm{Cu}$ deficiency, such as leaf curling and browning, are evident in the vegetative shoot [31]. Therefore, in this study, we focused on vegetative growth and on shoots because this is where the $\mathrm{Cu}$ demand for plastocyanin is high. It seems likely, though, that the role of $\mathrm{Cu}$-microRNAs, which are expressed in roots, stems, leaves, and flowers, is not limited to the vegetative shoot and indeed $\mathrm{Cu}$ feeding status is known to affect the timing of flowering, with deficient plants showing a delay [31]. Furthermore, $\mathrm{Cu}$ is also important for pollen development, presumably to allow for sufficient mitochondrial cytochrome-c oxidase activity [39]. We did not note any defect in fertility or seed set for our three target mimicry lines compared to wild-type. This was probably due to the sufficiency of $\mathrm{Cu}$ in the soil. It is possible that if the plants are to be subjected to $\mathrm{Cu}$ deficiency after the onset of flowering that a defect in pollen maturation would cause a decrease in fertility. However, such an experiment is difficult to control, and effects of both $\mathrm{Cu}$ and development would have to be considered simultaneously. Nevertheless, accumulation of mitochondrial COXII protein, one of three mitochondrial-encoded $\mathrm{Cu}$-binding core subunits of cytochrome-c oxidase in the respiratory electron transport chain [14], was clearly negatively affected by tandem target mimicry in the shoots. This observation indicates that optimal cytochrome-c oxidase activity under $\mathrm{Cu}$ deficiency requires functional $\mathrm{Cu}$-microRNAs. A role in regulating grain yield was also reported for miR408 in rice [42]. In this same study, overexpression of the rice miR408 target UCL8 (uclacyanin 8, a phytocyanin), showed a negative effect on plastocyanin and chloroplastic $\mathrm{Cu}$ accumulation in leaves [42].

In response to $\mathrm{Cu}$ availability, the $\mathrm{Cu}$-microRNAs are regulated directly by SPL7, which is the plant homolog of the chlamydomonas (CRR1) copper response regulator [43]. SPL7 and CRR1 regulation requires cis elements called $\mathrm{Cu}$-response elements (CuRe) with a GTAC core motif [43]. Thus, a strong mechanistic link exists for $\mathrm{Cu}$ and $\mathrm{Cu}$-microRNA regulation. Another identified transacting factor that directly mediates miR408 Cu-microRNA expression via promoter area binding is HY5 (elongated hypocotyl 5). Co-regulation was shown for miR408 by both SPL7 and HY5 [33,34]. This regulation makes sense since HY5 mediates gene expression in the light required for photosynthetic growth, which has a high demand for Cu. Plants that lack SPL7 or HY5 function had only a small defect in PC [34]. Overexpression of miR408 in the spl7 and hy5 mutants could, to some extent, alleviate this defect in PC maturation, albeit that plants were grown in vitro on agar media to see this effect [34]. Interestingly, miR408 overexpression could also rescue some developmental defects in hy5/spl7 lines [34]. Therefore, a feedback loop was proposed as a mechanism to allow better PC maturation in miR408-overproducing lines, but it can also be argued that an improved Cu economy in such lines allows for better $\mathrm{Cu}$ cofactor availability to PC [34]. Consistent with this idea are the observations reported in several plant species where miR408 expression causes higher chloroplast $\mathrm{Cu}$ content and improved photosynthesis, growth, and seed yield in diverse plant species $[42,44,45]$. On the other hand, Carrió-Seguí et al. have reported that both overexpression and loss of miR408 caused a diminished plant performance, especially in low Fe conditions [46].

Besides $\mathrm{Cu}$ availability, other environmental conditions have been reported to affect $\mathrm{Cu}$-microRNA expression [27]. This was convincingly shown in Arabidopsis for cold [47-49], Fe availability [46,50], or stresses that are predicted to induce reactive oxygen species accumulation such as high light, the herbicide methyl-viologen, and excessive toxic metal [29]. In our setup, we controlled growth 
conditions and attempted to avoid any additional stressors. It seems likely that Cu-microRNA expression is further tuned by environmental conditions apart from $\mathrm{Cu}$ and light. However, unlike for $\mathrm{Cu}$ and light, where cis-regions and interacting trans-acting factors (SPL7 and HY5) are identified, it is presently unclear at a mechanistic level how these conditions could be linked to gene expression of $\mathrm{Cu}$-microRNAs. Therefore, the effects of other stresses on $\mathrm{Cu}$ microRNAs could be direct or indirect. For $\mathrm{Fe}$, for instance, it is well-reported in the literature that lower $\mathrm{Cu}$ levels increases Fe uptake and vice versa. A mechanism for this interaction can be proposed based on the observation that both $\mathrm{Fe}$ and $\mathrm{Cu}$ uptake at the root require a reductase activity of the ferric reductase oxidase (FRO) family. A cross reactivity for the low $\mathrm{Cu}$-induced FRO4/FRO5 with $\mathrm{Fe}$, or for the low-Fe induced $\mathrm{FRO} 2$ with $\mathrm{Cu}$, would lead to increased $\mathrm{Cu}$ uptake under Fe deficiency, thus resetting the SPL7 regulation of $\mathrm{Cu}$ microRNAs, making it appear as if Fe regulates $\mathrm{Cu}$-microRNAs [8,51]. Therefore, to more directly link $\mathrm{Cu}$-microRNAs to other abiotic stresses, it will be important to uncover how potential cis-regions in the promoters and transacting factors interact to mediate stress response.

\section{Materials and Methods}

\subsection{Plant Material and Growth Conditions}

Lines were propagated on PRO-MIX HP soil that was fertilized with Miracle-Gro Liquid All Purpose Plant Food (Scotts Company, Marysville, OH, USA). Wild type (WT; Col.) and All3-mimicry transgenic lines seeds were surface-sterilized and germinated on agar plates containing one-half strength Murashige and Skoog (MS) medium [52] supplemented with 1\% sucrose. For hydroponics, 7-10 days old seedlings were placed on a one-tenth-strength Hoagland's solution prepared with deionized water [53]. The nutrient solution was aerated and was replaced each week. For copper depletion (deficiency), $\mathrm{Cu}$ was omitted from the nutrient solution, while $\mathrm{CuSO}_{4}$ was added to $5 \mathrm{nM}$ for low but sufficient $\mathrm{Cu}$ (sufficient for high PC activity, but with low CSD activity in the wild-type) and to $50 \mathrm{nM}$ for the $\mathrm{Cu}$-replete conditions (where all $\mathrm{Cu}$ proteins accumulate to maximum levels in the wild-type) [31]. To minimize $\mathrm{Cu}$ contamination, all containers and buckets used for $\mathrm{Cu}$-deprivation had never been in contact with $\mathrm{Cu}$. The plants were grown in a light intensity of $150 \mu \mathrm{mol} \mathrm{m}^{-2} \mathrm{~s}^{-1}$, with a 10-h-light/14-h-dark cycle and the temperature was maintained at $25^{\circ} \mathrm{C} \pm 2{ }^{\circ} \mathrm{C}$ in a climate-controlled room. After 4-weeks, plant material was harvested and stored frozen at $-80^{\circ} \mathrm{C}$ before analysis.

\subsection{Transgenic Lines}

Artificial target mimicry constructs were generated by modifying the sequence of the IPS1 gene [41]. The sequence of the construct, which was ordered as a synthesized piece of DNA (GenScript USA Inc. Piscataway, NJ, USA), is given in the Supplementary Materials. The All3-Cu miRNA target mimic construct was placed behind the CaMV 355 promoter in the pGWB41 vector, conferring resistance to kanamycin and hygromycin [54]. The construct was introduced into A. thaliana (accession Col-0) plants via a Agrobacterium tumefaciens-mediated transformation followed by selection on kanamycin containing agar media [55].

\subsection{Elemental Analysis}

For mineral content analysis, the plant tissue was placed in a drying oven at $55{ }^{\circ} \mathrm{C}$ for $48-72 \mathrm{~h}$. One hundred milligrams of the dried material was digested in $1 \mathrm{~mL}$ of trace element grade nitric acid and heated at $60{ }^{\circ} \mathrm{C}$ for $2 \mathrm{~h}$, followed by $130^{\circ} \mathrm{C}$ for $6 \mathrm{~h}$. The digests were subsequently diluted to $10 \mathrm{~mL}$ with double-distilled water before analysis using inductively coupled plasma - atomic emission spectrometry (ICP-AES) as described [56].

\subsection{Chlorophyll Fluorescence Measurements}

For chlorophyll fluorescence assays, whole rosettes of intact plants were used and dark-adapted for 30 minutes prior to analysis. Chlorophyll fluorescence imaging was done using a FluoroCam $701 \mathrm{MF}$ 
(Photon Systems International, Brno, Czech Republic) at an actinic light intensity of 150 micro-Einsteins as described [13]. The parameters $\Phi P S I I$ (flux through PSII, an estimate of photosynthetic electron the transport rate) and 1-qP (an estimate of the redox state of plastoquinone pool) were calculated as described [57].

\subsection{Protein Accumulation}

Soluble proteins were extracted as described [38]. Protein concentration was determined using the Pierce BCA protein assay kit (Thermo Scientific, Waltham, MA, USA) using bovine serum albumin as a standard. For western blotting, $20 \mu \mathrm{g}$ of total protein was separated using 15\% SDS-PAGE and then transferred onto a nitrocellulose membrane. Antibodies used for immunodetection of PC, CSD1, CSD2, and CCS have been described [13,37]. Antisera for COXII and cFBPase were obtained from Agrisera (Vannas, Sweden). All protein detection experiments were done at least in biological triplicate with comparable results, and representative gels are shown.

\subsection{Quantitative Reverse Transcription-PCR}

RNA from plants sampled in biological triplicate was isolated using the Trizol reagent following the manufacturer's recommended protocol (Life Technologies, Carlsbad, CA, USA). After determination of total RNA concentrations, equal amounts per sample were reverse-transcribed using a First Strand cDNA Synthesis Kit (Life Technologies) and random hexamer primers. Quantitative RT-PCR was performed using the Light Cycler SYBR Green 1 master mix (Life Technologies) using gene-specific primer pairs as described previously for Populus trichocarpa using actin 1 as a housekeeping reference gene [37]. Samples without a template were used as negative controls. All primers are listed in Supplementary Table S2. qRT-PCR results and quality controls were analyzed using Light-Cycler 480 data-analysis software (version 1.5.1, Roche, Basel, Switzerland). The $\Delta \Delta \mathrm{Ct}$ method was used to calculated relative transcript expression levels.

\subsection{Mature miRNA Stem-Loop qRT-PCR}

For the quantification of mature microRNAs, a stem-loop pulsed RT was used [37]. The RNA was extracted using the Trizol method as described above; however, ethanol washes were avoided and nucleic acid precipitation steps were carried out after addition of 1/10th volume of sodium acetate (3 M; pH 5.2), followed by an equal volume of isopropanol [37]. The stem-loop pulsed RT and miRNA qRT-PCR were performed as described previously [37,58]. miRNA397b, 398b/c, and 408 abundance were analyzed using gene-specific primers, as described previously for P. trichocarpa [37]; see Supplementary Table S2). Relative mature miRNA abundance was standardized using miR156 expression [37]. Each sample was analyzed in biological triplicate.

\subsection{Statistical Analysis}

For statistical analyses the JMP software package (version 9.0.2; SAS Institute, Cary, NC, USA) was used. All results represent the averages and SD from at least three independent biological replicates. A Student's $t$-test was used to calculate significant differences $(p<0.05)$.

\section{Conclusions}

Simultaneous inhibition of the function of three conserved $\mathrm{Cu}$-microRNAs caused a mild but significant growth phenotype on low-Cu media, which can be ascribed to a lack of function of plastocyanin, which is essential for photosynthesis. These observations provide support for a function of $\mathrm{Cu}$-microRNas is the $\mathrm{Cu}$ economy.

Supplementary Materials: The following are available online at http://www.mdpi.com/2223-7747/8/6/141/s1. Figure S1: Conceptual model for tandem target mimicry, Table S1: Mineral composition of lines under three Cu regimes in $\mathrm{mg} / \mathrm{kg} \mathrm{dw}$, Table S2: List of the primers used for qRT-PCR and mature miRNA stem-loop qRT-PCR. 
Author Contributions: Authors' contributions: M.S and M.P. conceived the research plans; M.S. did the experiments; M.S. and M.P. analyzed the data; M.S. drafted the first manuscript; M.P. supervised the overall project and finalized the writing.

Acknowledgments: This project was supported by the Agriculture and Food Research Initiative competitive grant 2012-67-13-19416 of the USDA National Institute of Food and Agriculture to M.P.

Conflicts of Interest: The authors declare no conflict of interest

\section{Abbreviations}

CSD, Cu/Zn-superoxide dismutase; COX, cytochrome-c oxidase; PSII, flux through PSII; FeSOD, iron superoxide dismutase; 1-qP, redox state of plastoquinone pool; LAC, laccase; PC, Plastocyanin.

\section{References}

1. Marschner, H. Mineral Nutrition of Higher Plants; Academic Press: London. UK, 1995.

2. Shikanai, T.; Muller-Moule, P.; Munekage, Y.; Niyogi, K.K.; Pilon, M. PAA1, a P-type ATPase of arabidopsis, functions in copper transport in chloroplasts. Plant Cell 2003, 15, 1333-1346. [CrossRef]

3. Tapken, W.; Ravet, K.; Pilon, M. Plastocyanin controls the stabilization of the thylakoid Cu-transporting P-type ATPase PAA2/HMA8 in response to low copper in Arabidopsis. J. Biol. Chem. 2012, 287, 18544-18550. [CrossRef] [PubMed]

4. Raven, J.A.; Evans, M.C.; Korb, R.E. The role of trace metals in photosynthetic electron transport in $\mathrm{O}_{2}$-evolving organisms. Photosynth. Res. 1999, 60, 111-149. [CrossRef]

5. Pesaresi, P.; Scharfenberg, M.; Weigel, M.; Granlund, I.; Schroeder, W.P.; Finazzi, G.; Rappaport, F.; Masiero, S.; Furini, A.; Jahns, P.; et al. Mutants, Overexpressors, and Interactors of Arabidopsis Plastocyanin Isoforms: Revised Roles of Plastocyanin in Photosynthetic Electron Flow and Thylakoid Redox State. Mol. Plant 2009, 2, 236-248. [CrossRef] [PubMed]

6. Abdel-Ghany, S.E. Contribution of plastocyanin isoforms to photosynthesis and copper homeostasis in Arabidopsis thaliana grown at different copper regimes. Planta 2009, 229, 767-779. [CrossRef]

7. Abdel-Ghany, S.E.; Muller-Moule, P.; Niyogi, K.K.; Pilon, M.; Shikanai, T. Two P-type ATPases are required for copper delivery in Arabidopsis thaliana chloroplasts. Plant Cell 2005, 17, 1233-1251. [CrossRef]

8. Bernal, M.; Casero, D.; Singh, V.; Wilson, G.T.; Grande, A.; Yang, H.; Dodani, S.C.; Pellegrini, M.; Huijser, P.; Connolly, E.L.; et al. Transcriptome sequencing identifies SPL7-regulated copper acquisition genes FRO4/FRO5 and the copper dependence of iron homeostasis in Arabidopsis. Plant Cell 2012, 24, 738-761. [CrossRef] [PubMed]

9. Molina-Heredia, F.P.; Wastl, J.; Navarro, J.A.; Bendall, D.S.; Hervás, M.; Howe, C.J.; De La Rosa, M.A. Photosynthesis: a new function for an old cytochrome? Nature 2003, 424, 33-34. [CrossRef]

10. Weigel, M.; Varotto, C.; Pesaresi, P.; Finazzi, G.; Rappaport, F.; Salamini, F.; Leister, D. Plastocyanin Is Indispensable for Photosynthetic Electron Flow in Arabidopsis thaliana. J. Biol. Chem. 2003, 278, 31286-31289. [CrossRef] [PubMed]

11. Kliebenstein, D.J.; Monde, R.-A.; Last, R.L. Superoxide dismutase in Arabidopsis: An eclecticenzyme family with disparate regulation and protein localization. Plant Physiol. 1998, 118, 637-650. [CrossRef]

12. Chu, C.C.; Lee, W.C.; Guo, W.Y.; Pan, S.M.; Chen, L.J.; Li, H.M.; Jinn, T.L. A copper chaperone for superoxide dismutase that confers three types of copper/zinc superoxide dismutase activity in Arabidopsis. Plant Physiol. 2005, 139, 425-436. [CrossRef]

13. Cohu, C.M.; Abdel-Ghany, S.E.; Gogolin Reynolds, K.A.; Onofrio, A.M.; Bodecker, J.R.; Kimbrel, J.A.; Niyogi, K.K.; Pilon, M. Copper delivery by the copper chaperone for chloroplast and cytosolic copper/zinc-superoxide dismutases: regulation and unexpected phenotypes in an Arabidopsis mutant. Mol. Plant 2009, 2, 1336-1350. [CrossRef]

14. Carr, H.S.; Winge, D.R. Assembly of Cytochrome $c$ Oxidase within the Mitochondrion. Acc. Chem. Res. 2003, 36, 309-316. [CrossRef]

15. Rodriguez, F.I.; Esch, J.J.; Hall, A.E.; Binder, B.M.; Schaller, G.E.; Bleecker, A.B. A copper cofactor for the ethylene receptor ETR1 from Arabidopsis. Science 1999, 283, 996-998. [CrossRef]

16. Alonso, J.M.; Stepanova, A.N. The Ethylene Signaling Pathway. Science 2004, 306, 1513-1515. [CrossRef]

17. Dong, J.; Kim, S.T.; Lord, E.M. Plantacyanin plays a role in reproduction in Arabidopsis. Plant Physiol. 2005, 138, 778-789. [CrossRef] 
18. Pignocchi, C.; Fletcher, J.M.; Wilkinson, J.E.; Barnes, J.D.; Foyer, C.H. The function of ascorbate oxidase in tobacco. Plant Physiol. 2003, 132, 1631-1641. [CrossRef]

19. Yamamoto, A.; Bhuiyan, M.N.; Waditee, R.; Tanaka, Y.; Esaka, M.; Oba, K.; Jagendorf, A.T.; Takabe, T. Suppressed expression of the apoplastic ascorbate oxidase gene increases salt tolerance in tobacco and Arabidopsis plants. J. Exp. Bot. 2005, 56, 1785-1796. [CrossRef]

20. Frébort, I.; Sebela, M.; Svendsen, I.; Hirota, S.; Endo, M.; Yamauchi, O.; Bellelli, A.; Lemr, K.; Pec, P. Molecular mode of interaction of plant amine oxidase with the mechanism-based inhibitor 2-butyne-1,4-diamine. Eur. J. Biochem. 2000, 267, 1423-1433.

21. Groß, F.; Rudolf, E.E.; Thiele, B.; Durner, J.; Astier, J. Copper amine oxidase 8 regulates arginine-dependent nitric oxide production in Arabidopsis thaliana. J. Exp. Bot. 2017, 68, 2149-2162. [CrossRef]

22. McCaig, B.C.; Meagher, R.B.; Dean, J.F. Gene structure and molecular analysis of the laccase-like multicopper oxidase (LMCO) gene family in Arabidopsis thaliana. Planta 2005, 221, 619-636. [CrossRef]

23. Turlapati, P.V.; Kim, K.W.; Davin, L.B.; Lewis, N.G. The laccase multigene family in Arabidopsis thaliana: towards addressing the mystery of their gene function(s). Planta 2001, 233, 439-470. [CrossRef] [PubMed]

24. Cai, X.; Davis, E.J.; Ballif, J.; Liang, M.; Bushman, E.; Haroldsen, V.; Torabinejad, J.; Wu, Y. Mutant identification and characterization of the laccase gene family in Arabidopsis. J. Exp. Bot. 2006, 57, 2563-2569. [CrossRef] [PubMed]

25. Berthet, S.; Demont-Caulet, N.; Pollet, B.; Bidzinski, P.; Cézard, L.; Le Bris, P.; Borrega, N.; Hervé, J.; Blondet, E.; Balzergue, S.; et al. Disruption of LACCASE4 and 17 Results in Tissue-Specific Alterations to Lignification of Arabidopsis thaliana Stems. Plant Cell 2011, 23, 1124-1137. [CrossRef]

26. Zhao, Y.; Lin, S.; Qiu, Z.; Cao, D.; Wen, J.; Deng, X.; Wang, X.; Lin, J.; Li, X. MicroRNA857 is Involved in the Regulation of Secondary Growth of Vascular Tissues in Arabidopsis. Plant Physiol. 2015, 169, 2539-2552. [CrossRef] [PubMed]

27. Pilon, M. The copper microRNAs. New Phytol. 2017, 213, 1030-1035. [CrossRef]

28. Jones-Rhoades, M.W.; Bartel, D.P.; Bartel, B. MicroRNAs and their regulatory roles in plants. Ann. Rev. Plant Biol. 2006, 57, 19-53. [CrossRef]

29. Sunkar, R.; Kapoor, A.; Zhu, J.-K. Posttranscriptional induction of two Cu/Zn superoxide dismutase genes in Arabidopsis is mediated by downregulation of miR398 and important for oxidative stress tolerance. Plant Cell 2006, 18, 2051-2065. [CrossRef]

30. Yamasaki, H.; Abdel-Ghany, S.E.; Cohu, C.M.; Kobayashi, Y.; Shikanai, T.; Pilon, M. Regulation of Copper Homeostasis by Micro-RNA in Arabidopsis. J. Biol. Chem. 2007, 282, 16369-16378. [CrossRef]

31. Abdel-Ghany, S.E.; Pilon, M. MicroRNA-mediated Systemic Down-regulation of Copper Protein Expression in Response to Low Copper Availability in Arabidopsis. J. Biol. Chem. 2008, 283, 15932-15945. [CrossRef]

32. Yamasaki, H.; Hayashi, M.; Fukazawa, M.; Kobayashi, Y.; Shikanai, T. SQUAMOSA Promoter Binding Protein-Like7 Is a Central Regulator for Copper Homeostasis in Arabidopsis. Plant Cell. 2009, 21, 347-361. [CrossRef] [PubMed]

33. Zhang, H.; Li, L. SQUAMOSA promoter binding protein-like7 regulated microRNA408 is required for vegetative development in Arabidopsis. Plant J. 2013, 74, 98-109. [CrossRef] [PubMed]

34. Zhang, H.; Zhao, X.; Li, J.; Cai, H.; Deng, X.W.; Li, L. MicroRNA408 is critical for the HY5-SPL7 gene network that mediates the coordinated respose to light and copper. Plant Cell 2014, 26, 4933-4953. [CrossRef]

35. Cuperus, J.T.; Fahlgren, N.; Carrington, J.C. Evolution and functional diversification of MIRNA genes. Plant Cell 2011, 23, 431-442. [CrossRef] [PubMed]

36. Waldron, K.J.; Rutherford, J.C.; Ford, D.; Robinson, N.J. Metalloproteins and metal sensing. Nature 2009, 460, 823-830. [CrossRef]

37. Ravet, K.; Danford, F.L.; Dihle, A.; Pittarello, M.; Pilon, M. Spatial-temporal analysis of Cu homeostasis in Populus trichocarpa reveals an integrated molecular remodeling for a preferential allocation of copper to plastocyanin in the chloroplasts of developing leaves. Plant Physiol. 2011, 157, 1300-1312. [CrossRef]

38. Shahbaz, M.; Ravet, K.; Peers, G.; Pilon, M. Prioritization of copper for the use in photosynthetic electron transport in developing leaves of hybrid poplar. Front. Plant Sci. 2015, 6, 407. [CrossRef]

39. Yan, J.; Chia, J.C.; Sheng, H.; Jung, H.I.; Zavodna, T.O.; Zhang, L.; Huang, R.; Jiao, C.; Craft, E.J.; Fei, Z.; et al. Arabidopsis Pollen Fertility Requires the Transcription Factors CITF1 and SPL7 That Regulate Copper Delivery to Anthers and Jasmonic Acid Synthesis. Plant Cell 2017, 29, 3012-3029. [CrossRef] 
40. Dugas, D.V.; Bartel, B. Sucrose induction of Arabidopsis miR398 represses two Cu/Zn superoxide dismutases. Plant Mol. Biol. 2008, 67, 403-417. [CrossRef]

41. Franco-Zorrilla, J.M.; Valli, A.; Todesco, M.; Mateos, I.; Puga, M.I.; Rubio-Somoza, I.; Leyva, A.; Weigel, D.; García, J.A.; Paz-Ares, J. Target mimicry provides a new mechanism for regulation of microRNA activity. Nat. Genet. 2007, 39, 1033-1037. [CrossRef]

42. Zhang, J.P.; Yu, Y.; Feng, Y.Z.; Zhou, Y.F.; Zhang, F.; Yang, Y.W.; Lei, M.Q.; Zhang, Y.C.; Chen, Y.Q. MiR408 Regulates Grain Yield and Photosynthesis via a Phytocyanin Protein. Plant Physiol. 2017, 175, 1175-1185. [CrossRef] [PubMed]

43. Kropat, J.; Tottey, S.; Birkenbihl, R.P.; Depege, N.; Huijser, P.; Merchant, S. A regulator of nutritional copper signaling in Chlamydomonas is an SBP domain protein that recognizes the GTAC core of copper response element. Proc. Natl. Acad. Sci. USA 2005, 102, 18730-18735. [CrossRef] [PubMed]

44. Pan, J.; Huang, D.; Guo, Z.; Kuang, Z.; Zhang, H.; Xie, X.; Ma, Z.; Gao, S.; Lerdau, M.T.; Chu, C.; et al. Overexpression of microRNA408 enhances photosynthesis, growth, and seed yield in diverse plants. J. Integr. Plant Biol. 2018, 60, 323-340. [CrossRef] [PubMed]

45. Song, Z.; Zhang, L.; Wang, Y.; Li, H.; Li, S.; Zhao, H.; Zhang, H. Constitutive Expression of miR408 Improves Biomass and Seed Yield in Arabidopsis. Front. Plant Sci. 2018, 8, 2114. [CrossRef] [PubMed]

46. Carrió-Seguí, À.; Ruiz-Rivero, O.; Villamayor-Belinchón, L.; Puig, S.; Perea-García, A.; Peñarrubia, L. The Altered Expression of microRNA408 Influences the Arabidopsis Response to Iron Deficiency. Front. Plant Sci. 2019, 10, 324. [CrossRef]

47. Sunkar, R.; Zhu, J.K. Novel and stress-regulated micro-RNAs and other small RNAs from Arabidopsis. Plant Cell 2004, 16, 2001-2019. [CrossRef]

48. Chen, Y.; Jiang, J.; Song, A.; Chen, S.; Shan, H.; Luo, H.; Gu, C.; Sun, J.; Zhu, L.; Fang, W.; et al. Ambient temperature enhanced freezing tolerance of Chrysanthemum dichrum CdICE1 Arabidopsis via miR398. BMC Biol. 2013, 11, 121. [CrossRef]

49. Guan, Q.; Lu, X.; Zeng, H.; Zhang, Y.; Zhu, J. Heat stress induction of miR398 triggers a regulatory loop that is critical for thermotolerance in Arabidopsis. Plant J. 2013, 74, 840-851. [CrossRef]

50. Waters, B.M.; McInturf, S.A.; Stein, R.J. Rosette iron deficiency transcript and microRNA profiling reveals links between copper and iron homeostasis in Arabidopsis thaliana. J. Exp. Bot. 2012, 63, 5903-5918. [CrossRef]

51. Robinson, N.J.; Procter, C.M.; Connolly, E.L.; Guerinot, M.L. A ferric-chelate reductase for iron uptake from soils. Nature 1999, 397, 694-697. [CrossRef]

52. Murashige, T.; Skoog, F. A revised medium for rapid growth and bio assays with tobacco tissue cultures. Physiol. Plant. 1962, 15, 473-497. [CrossRef]

53. Epstein, E.; Bloom, A. Mineral Nutrition in Plants: Principles and Perspectives, 2nd ed.; Sinauer Associates: Sunderland, MA, USA, 2005.

54. Nakagawa, T.; Kurose, T.; Hino, T.; Tanaka, K.; Kawamukai, M.; Niwa, Y.; Toyooka, K.; Matsuoka, K.; Jinbo, T.; Kimura, T. Development of series of gateway binary vectors, pGWBs, for realizing efficient construction of fusion genes for plant transformation. J. Biosci. Bioeng. 2007, 104, 34-41. [CrossRef] [PubMed]

55. Clough, S.J.; Bent, A.F. Floral dip: a simplified method for Agrobacterium-mediated transformation of Arabidopsis thaliana. Plant J. 1998, 16, 735-743. [CrossRef] [PubMed]

56. Pilon-Smits, E.A.; Hwang, S.; Lytle, C.M.; Zhu, Y.; Tai, J.C.; Bravo, R.C.; Chen, Y.; Leustek, T.; Terry, N. Overexpression of ATP sulfurylase in Indian mustard leads to increased selenite uptake, reduction and tolerance. Plant Physiol. 1999, 119, 123-132. [CrossRef]

57. Maxwell, K.; Johnson, G.N. Chlorophyll fluorescence-a practical guide. J. Exp. Bot. 2000, 51, 659-668. [CrossRef]

58. Varkonyi-Gasic, E.; Hellens, R.P. Quantitative stem-loop RT-PCR for detection of microRNAs. Methods Mol. Biol. 2007, 744, 145-157.

(C) 2019 by the authors. Licensee MDPI, Basel, Switzerland. This article is an open access article distributed under the terms and conditions of the Creative Commons Attribution (CC BY) license (http://creativecommons.org/licenses/by/4.0/). 